Resumo

\title{
Comparação biomecânica entre exercícios de agachamento com e sem sobrecarga
}

Samuel Oliveira Coelho Silva Bsci, Rodrigo Rico Bini PhD

Introdução: 0 uso de implementos de resistência elástica, apesar de amplamente difundido em programas de reabilitação funcional, é ainda incipiente nos programas de ganho de condicionamento neuromuscular e suas potencialidades e condições de emprego, ainda possuem campo para investigação.

Objetivo: 0 presente estudo investigou se uma faixa elástica de látex utilizada em um exercício de agachamento afundo estimula a produção de um pico de força equivalente á halteres de peso correspondente.

Métodos: Participaram deste estudo dez homens saudáveis $(19 \pm 1$ anos, 68,3 \pm $7,01 \mathrm{~kg}, 174 \pm 7,23 \mathrm{~cm}$ ), que realizaram três series de agachamento unilateral afundo, uma sem sobrecarga, uma com dois halteres de $6 \mathrm{~kg}$ e uma utilizando uma faixa elástica de cor dourada e graduação de resistência máxima. Os componentes da força de reação do solo foram medidos por duas plataformas de força, com cada membro inferior apoiado sobre uma plataforma e adquiridos utilizando programa computacional nativo das plataformas, com amostragem de $1000 \mathrm{~Hz}$. Os valores dos picos de força, separados nas fases concêntrica e excêntrica obtidos de cinco repetições, para cada modalidade de execução, foram comparados utilizando teste $t$ de Student para amostras pareadas com análise bilateral.

Resultados: 0 pico de força produzido foi aproximadamente $18 \%$ maior para o exercício realizado com os halteres em relação á faixa e ao exercício sem sobrecarga (para ambas as fases, $\mathrm{p}<0,01$ ). Não foi observada diferença significativa entre a força produzida utilizando a faixa elástica e o exercício realizado sem sobrecarga $(1 \%, p=0,50$ para a flexão e $0 \%, p=0,91$ para a extensão).

Conclusão: 0 exercício realizado com os halteres produz sobrecarga significativamente superior aos demais, tanto na fase excêntrica quanto concêntrica do movimento, não havendo diferenças entre o elástico e o exercício livre. 